\title{
Netsanet Yilma. \\ MA thesis abstracts from Addis Ababa University, Faculty of Journalism and Communication 2007
}

\author{
Advisors: Yacob Arsano and Terje S. Skjerdal \\ Thesis defended: August 2007 \\ E-mail: Netsanet Yilma <zerotiha@yahoo.com>
}

Title: A critical analysis of Ethiopian broadcasting media regulation 1991-2007

\begin{abstract}
This research attempts to look into what practical changes the broadcasting media in Ethiopia have experienced in light of media regulation policies, and if the intended changes have not taken place, attempts to point to reasons.
\end{abstract}

The period after the coming into power of EPRDF (Ethiopian People's Revolutionary Democratic Front), 1991 and onwards, marked a change in Ethiopian media politics. Of the reforms EPRDF made was liberalizing the media through granting different freedoms. This was done through various laws and policies. The 1992 press law that gave citizens the freedom to exercise freedom of expression through private print media, the 1999 broadcast proclamation, the 2003 press law and the newly endorsed broadcast proclamation of the year 2007 are the major policies introduced with regard to the media. The 1995 Ethiopian Constitution also is a monumental document for reinforcing freedom of expression in Ethiopia. Article 29 of the Constitution confirms that all citizens have the right to "seek, receive and impart information and ideas of all kinds regardless of frontiers, either orally, in writing or in prints in the form of art, or through any idea of his/her choice" (FDRE Constitution, Art 29).

After eight years of the endorsement of the first Broadcast Proclamation in 1999, which further affirms the full grant of the right to own a private broadcasting station, there is no private television station, and radio stations are still under the control of the control of the government in one way or another. Why are the broadcast media regulated severely while full freedom of expression is granted on other arenas? Data for the study was acquired from documents and personal interviews with actors in the media industry. The conclusion of the research include: private broadcasters and licensees do not work together; the new broadcasting regulation policy gives broadcasters a chance to appeal and imprisonment is excluded from the punitive articles.

\section{Mesay Berhanu}

\section{Title: Foreign news coverage in the Ethiopian print media}

\author{
Advisors: Yacob Arsano and Kristin Skare Orgeret \\ Thesis defended: August 2007 \\ E-mail: Mesay Berhanu <mesaybg@yahoo.com>
}

\begin{abstract}
This study explores the issues of the New World Information and Communication Order (NWICO) which were advocated by the Non-Aligned Movement comprised of countries in Africa, Asia and Latin America in the late 1970s and early 1980s. These countries complained about the inequalities and discrepancies in the existing world order particularly in the dominant international communications system.
\end{abstract}


Even though the demands of the Third World countries were ultimately diverted to the question of development assistance by the Western world, various researches have been conducted since then on the issues of international news flow and the coverage of the Third World in the Western media. However, there seems to be little research conducted on the coverage of the Third World in the media of the developing world themselves. Therefore, this research was embarked upon to assess the coverage of the developed versus the developing world in the print media is Ethiopia. The researcher selected six local English language newspapers in circulation at the time of the study. These newspapers included the Capital, The Ethiopian Herald, The Daily Monitor, Fortune, The Reporter and The Sub-Saharan Informer. Six editions of each of these newspapers representing six weeks in March and April 2006 were sampled, and all the foreign news appeared on the front and/or the inner pages of the each newspaper were analyzed quantitatively. A qualitative analysis of a purposely selected news items was also made to identify the roles and representations the developed and the developing world had in the foreign news coverage of the six newspapers. In-depth interviews were also conducted with representative editors and editors-in-chief of the five newspapers except that of Fortune.

The results of the study indicated that the developing world in general and Africa in particular had a wider coverage than the developed world, but the developed world had far more coverage than the developing world outside Africa. When the developing nations were further classified into medium and low categories of development according to the $2006 \mathrm{UN}$ Development Index report, the highly developed nations had far more coverage than either of the developing nations in the two categories. However, the individual newspapers showed significant variations to the extent that the coverage of these parts of the world in some of these newspapers contradicted the generalizations drawn above. These variations appeared to have been explained partly by the objectives of the newspapers, and the influence of the individual editors and editors-in-chief who were involved in the news selection processes. The use of sources in particular was found to be an important factor in determining the newspapers' coverage of the different parts of the world. Ownership, however, seems to have been loosely related to these variations in the extent and types of coverage given to the different parts of the world by the six newspapers analyzed in the study.

\title{
3. Tewodros Workalemahu
}

\section{Title: Consuming Disney and beyond:}

A study on the reception of children on a global media giant

\author{
Advisors: Amare Asgedom and Larry Strelitz \\ Thesis defended: August 2007 \\ E-mail: Tewodros Workalemahu <tewod2002@gmail.com>
}

\begin{abstract}
With the penetration of global media contents particularly Hollywood films in Ethiopia in the early 1990s and afterwards, local audiences have been able to be exposed to American movies. A significant part of this audience is made up of Ethiopian upper-middleclass children in Addis Ababa who are exposed and attracted to the animation features produced by the all time leading manufacturer of children's films and literature, the American-based Walt Disney Company. Disney Kids: A Study on the Reception of a Global
\end{abstract}

Media Giant by Ethiopian Children in Addis Ababa attempts to investigate how the specified 
children in Addis Ababa, in the midst of their everyday lived reality, make meaning out of the animation and cartoon films that are produced in another setting. The study, by using focus group interviews and in-depth individual interviews, explores how Ethiopian upper/middle-class children make sense out of global texts and images as represented by Disney in the context of their everyday life.

The findings of the study exhibit that local culture, values, and interests have a significant role to play in the interaction between the global and the local. Intricate responses of respondents reveal that there is no easy way of establishing a definitive nature of the global's penetration to the local. This challenges the fundamental premise of the media imperialism thesis that the authentic, traditional and local culture of 'Third World' countries like Ethiopia are becoming battered out of existence as a result of the dumping of large quantities of media products by Western, particularly American, media conglomerates like that of the Walt Disney Company.

\title{
4. Frehiwot Yilma
}

\section{Title: Audience reception of the 'Shai Buna' talk show}

\author{
Advisors: Gebremedhin Simon and Larry Strelitz
}

Thesis defended: August 2007

E-mail: Frehiwot Yilma <frity48@yahoo.com>

Abstract: The talk shows as a media genre emerged in the western media around the 1960s. The genra has been on air on Ethiopian television since 1999. There are now four talk shows aired on the national television channel ETV, and the number is increasing.

This study is conducted to find out how audiences of the 'Shai Buna' talk show understand the talk show and the factors that account for their reception. Active audience theory was used as a framework to conduct the research. Audiences do not simply accept a message. They have the ability to accept or oppose a message.

Qualitative research methods, specifically focus group interviews and individual in-depth interviews were used to undertake the study. Generally, most of the respondents agreed that the show is about Ethiopian problems and their solutions. Respondents regardless of their differences seemed to understand the talk show similarly.

The results of the study revealed that live contexts play a major role in interpreting messages. Respondents make meaning depending on what is relevant to their daily life. Occupation, gender and age are among the factors which shape interpretations. However, there can be a understanding of the intended message by respondents depending on the similarity of opinions that both the producer and receiver of the message have on specific points of discussion. 


\section{Tereza Nega}

\section{Title: A reception study of female magazine readers: Kalkidan readers in focus}

Advisors: Gebremedhin Simon and Elna Rossouw

Thesis defended: August 2007

E-mail: Tereza Nega <terezamichaelisc@gmail.com>

Abstract: This study was conducted to explore the reception of female readers of the Kalkidan magazine in Addis Ababa, Ethiopia.

A qualitative research method was used in the form of a reception analysis. The study used a three stage qualitative approach, which include qualitative content analysis to make a comparative analysis of the content data with the audience data, focus group discussions followed by individual-in-depth interviews - the former to gather data through the groups' interaction and the latter to enrich the data and give it a 'human face'. The sampling procedure was mainly purposive. The gathered data finally were thematically analysed. In addition, though the study is not bound to specific theories attention was given to theoretical and epistemological issues entailed in reception research during analysis.

In general, the study elicited important insights in the understanding of the consumption of Kalkidan by female readers. It indicates that social factors such as age, education level and marital status affect the interpretation and consumption of the magazine by the women. The findings also reflect both the active and passive audience theories, basically related to the education factor. Some concepts of Hall's encoding/decoding model are also observed in the findings. The overall views of the women on the magazine in line with their level of satisfaction on the magazine are also included. Accordingly the study reflects what the magazine lacks to meet the lived contexts of the women.

The study shows that factors such as age, education and marital status affect the interpretation and use of the magazine by the women. Moreover, the findings reflect that both the active and the passive audience theories are basically related to the education factor. The study also highlighted that educated audiences are generally unsatisfied with the provisions of the magazine as they felt that it has lacked pertinence to their real lives. 